màng bồ đào ngay cả trước khi phẫu thuât. Các mắt được đưa vào nghiên cứu không đáp ứng với điều trị nội khoa để cắt cơn hoàn toàn do vậy trên thực tế chúng tôi đang phẫu thuật trên mắt còn viêm chưa được kiểm soát hoàn toàn. Trong nghiên cứu này, để hạn chế tình trạng viêm này, trước phẫu thuật chúng tôi đã tiến hành điều trị chống viêm tại chỗ và toàn thân cho bệnh nhân bằng corticoid, và tương tự sau mổ cũng điều trị hết sức tích cực cả đường tra tại mắt và đường tĩnh mạch. Tìm hiểu về các yếu tố liên quan tới biến chứng VMBĐ này chúng tôi thấy rằng chúng xuất hiên nhiều hơn trên mắt có tăng nhãn áp kéo dài hơn (trên 3 ngày). Hơn nữa, trong phẫu thuật này có tác động vào mống mắt do vậy, nguyên nhân gây VMBĐ lại được cộng hợp. Việc điêu trị gặp nhiều khó khắn, cần điều trị lâu dài, thời gian điều trị trung bình đến khi hết dấu hiệu viêm (cương tụ rìa, phản ứng thể mi, tyndal -) trong nghiên cứu của chúng tôi là $21,73 \pm 11,46$ (12-38 ngày). Do vậy, cần theo dõi bệnh nhân chu đáo để giải quyết triệt để biến chứng này

Ngoài ra, khi đánh giá ảnh hưởng của tai biến, biến chứng lê kết quả phẫu thuật, chúng tôi không thấy sự khác biệt giữa nhóm có biến chứng và nhóm không có biến chứng, điều này cho thấy hiệu quả của việc phát hiện và xử lý biến chứng sớm có ý nghĩa hết sức quan trọng đến kết quả phẫu thuật cuối cùng

\section{KẾT LUÂNN}

Phẫu thuật cắt bè vẫn là phẫu thuật có ý nghĩa trong kiểm soát nhãn áp trong điều trị glôcôm góc đóng cơn cấp không cắt cơn không kèm theo đục thể thủy tinh, tuy nhiên tỷ lệ tai biến, biến chứng cao cân theo dõi phát hiện và phối hợp với các biện pháp điêu trị bổ sung kịp thời.

\section{TÀI LIẸU THAM KHẢO}

1. Foster, Paul J. The epidemiology of primary angle closure and associated glaucomatous optic neuropathy. Seminars in ophthalmology. Vol. 17. No. 2. Taylor \& Francis, 2002

2. Nongpiur ME, Ku JY, Aung T. Angle closure glaucoma: a mechanistic review. Curr Opin Ophthalmol; 22:96-101. 2011

3. Edmunds, B., et al. The national survey of trabeculectomy. III. Early and late complications. Eye 16.3: 297-303. 2003

4. Nguyến Quốc Đat, Nghiên cứu các biến chứng trong phẫu thuật Phaco phối hợp cắt bè củng mạc giác mac. Tap chí y hoc Việt Nam, 1859 - 1868, $391,5,275-284.2017$

5. Aung T, Tow SL, Yap EY, et al. Trabeculectomy for acute primary angle closure. Ophthalmology.107(7):1298-302. 2000

6. Tan AM, Loon SC, Chew PT. "Outcomes following acute primary angle closure in an Asian population". Clin Exp Ophthalmol. 37(5):467-72. 2009

7. G L Spaeth. Trabeculectomy for acute primary angle closure. Ophthalmology; 108(6):1008. 2001

8. Sousa, David Cordeiro, and Luís Abegão Pinto. Trabeculectomy-Prevention and Management of Complications. Journal-Trabeculectomy-Prevention and Management of Complications. 2018

\title{
THỰC HÀNH XỬ TRÍ CỦA ĐIỀU DƯỠNG BỆNH VIỆN ĐA KHOA TRUNG TÂM AN GIANG SAU PHO'I NHIỄM VỚI MÁU, DICH CO' THỂ, 2020
}

\section{TÓM TẮT}

Nguy cơ nhiễm vi rút viêm gan Bở nhân viên y tế luôn mức cao do thường xuyên phải tiếp xúc với máu, dịch tiết của người bệnh bị nhiêm vi rút viêm gan $B$. Để giảm tỷ lệ mắc bệnh viêm gan vi rút $B$ nghề nghiêp , bên canh tiêm phòng vắc xin,các biện pháp dự phòng lây nhiểm đóng vai trò rất quan trọng. Nghiên cứu thực hành xử trí cuả điều dưỡng lâm sàng sau phơi nhiếm với máu, dịch cơ thể được thực hiện tại Bênh viện đa khoa trung tâm An Giang năm 2020 . Nghiển cứu mô tả cắt ngang sử dụng phương pháp định lượng trên 385 điêu dưỡng lâm sàng của bệnh

${ }^{1}$ Trường Đại học Y tế công cộng

${ }^{2}$ Bênh viên Đa khoa trung tầm An Giang

Chịu trách nhiệm chính: Nguyễn Ngọc Bích

Email: nnb@huph.edu.vn

Ngày nhân bài: 6.5.2021

Ngày phản biên khoa hoc: 25.6.2021

Ngày duyệt bài: 5.7.2021
Nguyễn Ngọc Bích ${ }^{1}$, Phạm Hữu Kiệt ${ }^{2}$

viện. Kết quả nghiên cứu cho thấy $64,6 \%$ điều dưỡng thực hành đúng xử trí sau phơi nhiễm với vật sắc nhon hoăc máu, dich cơ thể. Tăng cường kiểm tra giám sát thường xuyên về các quy trình kỹ thuật đều dưỡng, quy trình kiểm soát nhiêm khuẩn và các quy trình phòng ngừa chuẩn trong bệnh viện, nhất là những trường hợp bị tai nạn nghề nghiệp thì cần phải báo cáo ngay và đúng quy trình để có hướng xử trí kịp thời. Từ khoá: xử trí sau phơi nhiếm, điêu dương, bệnh viện, viêm gan B nghề nghiệp

\section{SUMMARY}

PRACTICE AFTER EXPOSURE TO BLOOD AND OTHER PATIENT'S MUCUS AMONG NURSES AT AN GIANG HOSPITAL, 2020

Health workers are at high risk of having Hepatitis B as they expose to blood and other patient's mucus. To reduce the risk of Hepatitis B and other occupaitonal blood - borne diseases, beside vaccination, applying different preventive measures 
are very critical. This study was conducted to explore practice among nurses of An Giang hospital after exposed to blood and other patient's mucus. Crosssectional study was designed and conducted among 385 nurses of the hospital. The results show that only $64.6 \%$ of nurses practiced adequately after exposing to blood or other mucus or get injured by needles. It was recommended that mornitoing should be strengthen especially report on injured cases should be implemented strickly.

Keyword: practice, post exposure, nurses, hospital, hepatitis B

\section{I. ĐĂT VẤN ĐỀ}

Bệnh viêm gan vi rút $B$ nghề nghiệp (VGVRB) đang được rất quan tâm hiện nay vì đặc tính tiến triển trầm lặng và hậu quả rất nặng nề cho người bị bệnh, bệnh viêm gan vi rút $B$ do yếu tố nghề nghiệp được công nhận là một trong 34 bệnh nghề nghiệp được bảo hiểm tại Việt Nam. Nhân viên y tế là đối tượng có nguy cơ lây nhiễm HBV rất cao, NVYT là lực lượng lao động thường xuyên trong bệnh viện bao gồm bác sĩ, dược sĩ, điều dưỡng, kỹ thuật viên... nhưng điều dưỡng là người thường xuyên trực tiếp chăm sóc cho bệnh nhân. Công việc chính là làm các thủ thuật như truyền dịch, tiểm thuốc, lấy máu...nên đầy là đối tượng có nguy cơ cao sẽ lây truyền các bệnh truyền nhiễm trong đó có bệnh viêm gan vi rút $\mathrm{B}(1)$.

Nhân viên y tế là đối tượng có nguy cơ nhiễm VGVRB rất cao. Tỉ lệ NVYT nhiễm VGVRB trong nghiên cứu tại miền Bắc của Khúc Xuyền là $13,1 \%$ (2), miền Trung của Viên Chinh Chiến là 17,6\% (3), miền Nam bệnh viên Nhân Dân Gia Định là $39 \%$ (4). Nguy cơ nhiễm VGVRB cao là tổn thương da bao gồm: Tiêm dưới da, mảnh thủy tinh, mũi kim khâu, lấy máu tĩnh mạch... Ngoài ra còn có dịch cơ thể bắn vào niêm mạc mắt, mũi, miệng, da trây xước hoặc các vết thương hở do tiếp xúc với máu hoặc sản phẩm của máu nhiễm HBV. HBV có khả nằng sống lâu nhiều tháng trong vết máu khô, VGVRB có khả năng lây nhiễm gấp 50-100 lần so với HIV $\left({ }^{8,9}\right)$.

Nghiên cứu được thực hiện với mục tiêu tìm hiểu thực hành xử trí của điêuu dưỡng lâm sàng tại bệnh viện đa khoa trung tâm An Giang sau khi phơi nhiễm với máu, dịch cơ thể để phòng ngừa viêm gian $B$ nghề nghiệp.

\section{II. ĐỐI TƯợNG VÀ PHƯƠNG PHÁP NGHIÊN CỨU}

2.1. Đối tượng nghiên cứu. Điều dưỡng đang công tác tại các khoa lâm sàng Bệnh viện Đa khoa trung tâm An Giang.

\subsection{Thời gian và địa điểm nghiên cứu}

Thời gian nghiên cứu: Từ tháng 03/2020 đến tháng 6/2020
Địa điểm nghiên cứu: Bệnh viện Đa khoa trung tâm An Giang địa chỉ 60 Ung Văn KhiêmMỹ phước-TP Long Xuyên-An Giang.

\subsection{Phương pháp nghiên cứu:}

Thiết kế nghiên cứu: Nghiên cứu mô tả cắt ngang

2.4. Cõ̃ mẫu, phương pháp chọn mẫu

Cỡ mẫu. Sử dụng công thức tính cõ mẫu cho một tỷ lể

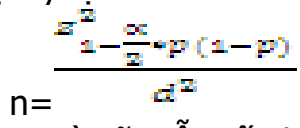

n: Là cõ̃ mẫu tối thiểu cần nghiên cứu

$\mathrm{d}$ : Sai số cho phép, chọn $\mathrm{d}=0.05$

Z: Giá trị tương ứng của hệ số tin cậy: $Z=1$, 96 ( $a=0,05$; độ tin cậy 95\%)

$\mathrm{p}$ : là tî lệ điều dưỡng kiến thức, thực hành dự phòng VGVRBnghề nghiệp đúng, theo nghiên cứu của Nguyễn Thị Mỹ Khánh Bệnh viện Nguyễn Đình Chiểu Bến Tre thì tỉ lệ kiến thức đạt $63,5 \%$, tỉ lệ thực hành dự phòng đạt $64,2 \%$ (do tỉ lệ tương đồng), nên học viên chọn $p=0,65$ làm tròn số.

Sau khi tính toán ta có kết quả $n=350$ điều dưỡng và ước tính $10 \%$ tỷ lệ bỏ cuộc hoặc trả lời không đầy đủ câu hỏi. Vậy cỡ mẫu nghiên cứu là $\mathrm{n}=385$ điều dưỡng.

Trong tổng số gần 470 điều dưỡng trong bênh viện, có 387 điều dưỡng làm việc tại các khoa lâm sàng, còn lại điêuu dưỡng làm tại các khoa cận lâm sàng và các phòng chức năng (trong đó có 2 điều dưỡng nghỉ hậu sản), do đó cũngtương đương với cõ̃ mẫu học viên vừa tính đượclà 385 điều dương.

\subsection{Phương pháp thu thập số liệu}

2.5.1.Công cự thu thập số liệu định lượng. Sử dụng bộ câu hỏi tự điền được thiết kễ sẵn, phát vấn cho các điều dưỡng đang làm tại các khoa lâm sàng Phiếu phát vấn được xây dưng theo 3 phần:

- Thông tin chung: Gồm 13 câu (từ E1 đến E13).

Để đánh giá thực hành dự phòng viêm gan vi rút $B$ nghề nghiệp, học viên dựa vào các văn bản, quy định, quy trình phòng ngừa chuẩn của Bộ Y tế. Bộ câu hỏi được thiết kế theo mục tiêu nghiên cứu có tham khảo tài liệu về dự phòng viêm gan vi rút $B$ nghề nghiệp của một số tác giả như: Phan Công Trắng (2018), Trân Thị Bích Hải (2013), Nguyễn Thị Mỹ Khánh $(2018)(5,6,7)$.

Đánh giá thực hành xử trí khi bị tai nạn nghề nghiệp:

- Phần thực hành xử trí khi bị tai nạn do vật sắc nhọn: Câu E54 và E55, mỗi câu tương ứng với 5 điểm, điểm tối đa cho phần đánh giá thực 
hành là 10điểm. Thực hành đúng $\geq 8,75$ điểm; không đúng $<8,75$ điểm (trong đó câu 54 đúng 3 ý 2-3-4 mới được tính điểm đúng).

- Phần thực hành xử trí khi bị dính, văng bắn máu/dịch: Câu E59 và E60, mỗi câu tương ứng với một số điểm nhất định, điểm tối đa cho phần đánh giá thực hành là 10 điểm. Thực hành đúng $=10$ điểm; không đúng < 10 điểm.

- Đánh giá thực hành xử trí chung đúng khi bị tai nạn nghề nghiệp: Xử trí đúng khi bị tai nạn do vật sắc nhọn hoặc khi bị dính, văng bẳn máu/dịch hoặc xử trí đúng cả hai tai nạn khi bị cả hai tai nạn nghề nghiệp (do vật sắc nhọn và dính, văng bắn máu/dịch).

\section{Thu thập số liệu}

- Trước khi thu thập số liệu hai tuần, NCV lập danh sách điều dưỡng các khoa lâm sàng từ phòng Tổ chức cán bộ và đồng thời báo cho điều dưỡng trưởng các khoa biết để mời đầy đủ các điều dưỡng tham gia nghiên cứu thực hiện một ngày nhất định.

- Sau mỗi buổi giao ban sáng của các khoa, nhóm nghiên cứu đã đến từng khoa vào một ngày đã được hẹn trước, mời các đối tượng nghiên cứu trả lời bộ câu hỏi thiết kế sẵn và được hiệu chỉnh, nghiên cứu viên đã thông báo mục đích của nghiên cứu và trả lời phiếu khảo sát theo sự hướng dẫn của nghiên cứu viên, điều tra viên, sau đó đưa cho ĐTNC đọc thông tin trong phiếu " đồng ý tham gia phát vấn nghiên cứu", nếu chấp nhận thì ký tên vào ô đồng ý và phát phiếu tự điền.

- Trong quá trình điền phiếu, nghiên cứu viên hướng dân cách trả lời phiếu rõ ràng, giải thích thông tin mà ĐTNC chưa rõ, quan sát không để cho ĐTNC trao đổi với nhau sẽ hưởng đến kết quả nghiên cứu.

- Khi ĐTNC đã điên xong, điều tra viên kiểm tra thông tin trên phiếu có đầy đủ và đúng chưa, trong trường hợpcòn thiếu hay nghi ngờ về thông tin, ĐTV yêu cầu ĐTNC bổ sung hay điêu chỉnh.

Sau khi thu thập, phiếu điều tra được kiểm tra đầy đủ sau đó nghiên cứu viên tiến hành làm sạch, mã hóa và nhập số liệu bằng phần mềm EpiData 3.1 và xử lý số liệu bằng phần mềm SPSS 20.0

2.7. Đạo đức nghiên cứu. Nghiên cứu được tiến hành đúng theo quy trình xét duyệt của hội đồng Đạo đức- Trường Đại học $Y$ tế cộng cộng, được Hội đồng Đạo đức trong nghiên cứu y sinh học của trường thông qua trước khi được tiến hành tại Bệnh viện Đa khoa trung tâm An Giang (Quyết đinh số 59/2020/YTCC- HD3 ngày 27 tháng 02 năm 2020 về việc chấp thuận các vấn đề đạo đức y sinh học).

\section{KẾT QUẢ NGHIÊN CỨU}

Bảng 3. 1. Đặc điểm về nhân khẩu học của đối tượng nghiên cứu ( $n=385$ )

\begin{tabular}{|c|c|c|}
\hline Các đặc trưng chung & $\begin{array}{c}\text { Tân số } \\
\text { (n) }\end{array}$ & $\begin{array}{c}\text { Tỉ lệ } \\
\mathbf{( \% )}\end{array}$ \\
\hline Giới tính: Nam & 152 & 39,5 \\
\hline Nữ & 233 & 60,5 \\
\hline Nhóm tuối: $21-29$ & 105 & 27,3 \\
\hline $30-39$ & 176 & 45,7 \\
\hline $40-49$ & 59 & 15,3 \\
\hline$\geq 50$ & 45 & 11,7 \\
\hline \multicolumn{2}{|c|}{}
\end{tabular}

\section{Trình độ chuyên môn}

\begin{tabular}{|c|c|c|}
\hline Đaai học & 75 & 19,5 \\
\hline Cao đắng & 55 & 14,3 \\
\hline Trung học chuyên nghiêp & 255 & 66,2 \\
\hline
\end{tabular}

Kết quả bảng 3. 1 cho thấy đối tương tham gia nghiên cứu chủ yếu là nữ $(60,5 \%)$ chiếm gần $2 / 3$ nam giới $(39,5 \%)$. Về nhóm tuổi của điêu dưỡng tham gia nghiên cứu, nhóm trẻ nhất từ 21-29 tuổi $(27,3 \%)$, kế đến là nhóm tuổi từ 3039 là nhóm tập trung nhiều nhất $(45,7 \%)$, tiếp theo là nhóm tuổi $40-49$ chiếm $(15,3 \%)$, sau cùng là nhóm trên 50 chỉ chiếm $(11,7 \%)$. Điều dưỡng nhỏ tuổi nhất là 21 và lớn nhất là 58 . Về trình độ chuyên môn của điều dưỡng chủ yếu là trung học chiếm $2 / 3(66,2 \%)$, còn lại là cao đẳng và đại học chiếm $(33,8 \%)$, không có sau đại học làm công tác lâm sàng.

Bảng 3. 2. Đặc điểm công việc của đôi tượng nghiên cứu $(n=385)$

\begin{tabular}{|c|c|c|}
\hline Nội dung & $\begin{array}{c}\text { Tân số } \\
\text { (n) }\end{array}$ & $\begin{array}{l}\text { Tỷ lệ } \\
(\%)\end{array}$ \\
\hline \multicolumn{3}{|l|}{ Khối công tác } \\
\hline Khối nội & 278 & 72,2 \\
\hline Khối ngoại & 1076 & 27,8 \\
\hline \multicolumn{3}{|c|}{ Thâm niên công tác } \\
\hline$\leq 5$ năm & 105 & 27,3 \\
\hline $6-10$ năm & 82 & 21,3 \\
\hline $11-19$ năm & 128 & 33,2 \\
\hline$\geq 20$ năm & 70 & 18,2 \\
\hline \multicolumn{3}{|c|}{ Công việc đang làm } \\
\hline Tiêm truyền & 364 & 94,5 \\
\hline Lấy bệnh phẩm (máu/dịch) & 303 & 78,7 \\
\hline Cho người bênh uống thuốc & 227 & 59,0 \\
\hline Làm thủ thuật & 271 & 70,4 \\
\hline Cọ rửa dụng cụ & 191 & 49,1 \\
\hline Xét nghiệm bệnh phấm & 159 & 41,3 \\
\hline $\begin{array}{l}\text { Xử lý quần áo, chăn } \\
\text { của người bệnh }\end{array}$ & 136 & 35,3 \\
\hline Dọn dẹp rác thải y tế sắc nhọn & 147 & 38,2 \\
\hline \multicolumn{3}{|c|}{ Tiền căn tiêm ngừa } \\
\hline Đã tiêm ngừa & 168 & 36,1 \\
\hline
\end{tabular}




\begin{tabular}{|c|c|c|}
\hline Chưa tiêm đủ & 23 & 7,7 \\
\hline Chưa tiêm ngừa & 108 & 28,1 \\
\hline
\end{tabular}

Tổng số điêuu dưỡng tham gia nghiên cứu chủ yếu làm ở khối nội chiếm gân $3 / 4(72,2 \%)$, còn lại là khối ngoại (27,8\%).

Thâm niên công tác của điều dưỡng trong ngành y tế $\leq 5(27,3 \%)$, còn lại từ 6 năm trở lên $(72,7 \%)$. Đi làm trong môi trường y tế thấp nhất là 1 năm, cao nhất là 38 năm, trung bình là 11,9 năm.

Những công việc ĐD đang làm tực tiếp trong môi trường bệnh viện có ảnh hưởng đến mức độ phơi nhiễm bệnh là rất cao. Trên $80 \%$ ĐD thường xuyên làm các công việc phải tiếp xúc với máu/dịch của người bệnh như: Truyền dịch, lấy bệnh phẩm, làm thủ thuật... Ngoài ra còn phải cọ rửa dụng cụ, dọn dẹp rác thải y tế.

Có $77,7 \%$ ĐD đã xét nghiệm HBsAg, trong đó $64,2 \%$ đã tiêm ngừa đầy đủ đúng lịch.

Theo kết quả nghiên cứu, hâu hết gân 100\% ĐD đã biết được về nguy cơ phơi nhiếm và mắc bệnh VGVRB của NVYT trong quá trình làm việc.

Bảng 3.3. ĐD thường bị tổn thương do vật sắc nhọn, dính, văng, bắn máu/dịch trong 6 tháng gần đây $(n=385)$

\begin{tabular}{|c|c|c|c|c|c|c|}
\hline \multirow{3}{*}{ Tai nạn nghề nghiệp } & \multicolumn{6}{|c|}{ Thực hành } \\
\hline & \multicolumn{2}{|c|}{ Có } & \multicolumn{2}{|c|}{ Không } & \multicolumn{2}{|c|}{ Không nhớ } \\
\hline & $\mathbf{n}$ & $\%$ & $\mathbf{n}$ & $\%$ & $\mathbf{n}$ & $\%$ \\
\hline Tốn thương do vật sắc nhọn & 60 & 15,6 & 317 & 82,3 & 8 & 2,1 \\
\hline Do dính, văng bằn máu/dịch & 115 & 29,9 & 266 & 69,1 & 4 & 1,0 \\
\hline \multirow{2}{*}{$\begin{array}{l}\text { Tổng TNNN điều dưỡng bị trong } \\
6 \text { tháng gân đây }\end{array}$} & \multicolumn{2}{|c|}{ Không tai nạn } & \multicolumn{2}{|c|}{ Một tai nạn } & \multicolumn{2}{|c|}{ Hai tai nạn } \\
\hline & 225 & 58,4 & 147 & 38,2 & 14 & 3,6 \\
\hline
\end{tabular}

Điều dưỡng bị tổn thương do vật sắc nhọn trong 6 tháng gần đây là chủ yếu do kim tiêm gây ra $(71,7 \%)$ và bị văng bắn máu/dịch của người bệnh. Trong đó có 12 trường hợp là không nhớ có bị tai nạn nghề nghiệp hay không. Từ kết quả phân tích cho thây có 60 trường hợp bị tổn thương do vật sắc nhọn và 115 trường hợp bị dính, văng, bẳn máu/dịch của người bệnh.

Trong tổng số 385 điều dưỡng tham gia nghiên cứu, khi được hỏi trong 6 tháng gần đây có bị TNNN do bị vật sắc nhọn đâm hay bị dính, văng , bắn máu/dịch của người bệnh không? Trong đó có 147 trường hợp bị một tai nạn $(38,2 \%), 14$ trường hợp bị cả hai tai nạn $(3,6 \%)$, không bị tai nạn nào 225 trường hơp $(58,4 \%)$.

Bảng 3.4.Thức hành xứ trí khi phơi nhiếm do vật sắc nhọn $(n=60)$

\begin{tabular}{|c|c|c|}
\hline Nội dung & $\begin{array}{c}\text { Tần số } \\
(\mathbf{n})\end{array}$ & $\begin{array}{l}\text { Tỷ lêe } \\
(\%)\end{array}$ \\
\hline \multicolumn{3}{|c|}{ Xử trí khi bị phơi nhiếm } \\
\hline Bóp/nặn máu vùng tốn thương & 11 & 18,3 \\
\hline $\begin{array}{l}\text { Xối ngay vết thương hoăc vùng } \\
\text { bị văng dính dưới vòi nước }\end{array}$ & 60 & 100 \\
\hline $\begin{array}{c}\text { Đế vết thương chảy máu trong } \\
\text { một thời gian ngắn }\end{array}$ & 35 & 58,3 \\
\hline $\begin{array}{l}\text { Rưa kỹ bằng xà phòng và nước } \\
\text { hoặc nước sát khuẩn, lau lại } \\
\text { bằng cồn }\end{array}$ & 60 & 100 \\
\hline Băng kín vết thương & 48 & 80,0 \\
\hline \multicolumn{3}{|l|}{ Thời gian xử trí } \\
\hline $\begin{array}{l}\text { Ngay sau khi bị tai nạn do vật } \\
\text { sắc nhọn }\end{array}$ & 58 & 96,7 \\
\hline Thực hành xử trí khi bị ph & i nhíc & \\
\hline
\end{tabular}

\begin{tabular}{|c|c|c|}
\hline \multicolumn{3}{|c|}{ vật sắc nhọn } \\
\hline Đúng & 36 & 60 \\
\hline Không đúng & 24 & 40 \\
\hline
\end{tabular}

Khi bị tai nạn do vật sắc nhọn (100\%) điều dưỡng biết cách xử trí là xối ngay vết thương dưới vòi nước chảy và rửa kỹ bằng xà phòng hoặc nước sát khuẩn sau đó lau lại bằng cồn, kễ đến $(80 \%)$ điều dưỡng biết cách băng kín vết thương lại. Tuy nhiên vẫn còn $(18,3 \%)$ điều dưỡng đã bóp/nặn máuvùng tổn thương.

Trong 60 trường hợp bị tai nạn do vật sắc nhọn có $(60,0 \%)$ điều dưỡng xử trí đúng yêu câu (điểm đạt $8,75 / 10$, trong đó bắt buộc phải đạt 3 ý 2-3-4 trong câu 54 quy trình xử trí, đồng thời đúng thời gian xử trí), bên cạnh đó có(40\%) không xử trí đúng yêu cầu.

Bảng 3.5.Thực hành xứ trí khi bi dính, văng bắn máu/dịch ( $n=115)$

\begin{tabular}{|c|c|c|}
\hline Nội dung & $\begin{array}{c}\text { Tần } \\
\text { số (n) }\end{array}$ & $\begin{array}{l}\text { Tỷ lệ } \\
(\%)\end{array}$ \\
\hline \multicolumn{3}{|c|}{$\begin{array}{l}\text { Xử trí đâu tiên khi bị dính, văng bằn } \\
\text { máu/dịch }\end{array}$} \\
\hline Lây bông, gạc lau máu/dịch & 33 & 28,7 \\
\hline $\begin{array}{l}\text { Rứa sach ngay nơi tiếp xúc với } \\
\text { máu/dịch aua bệnh nhân bằng nước }\end{array}$ & 82 & 71,3 \\
\hline \multicolumn{3}{|l|}{ Thời gian xử trí } \\
\hline $\begin{array}{l}\text { Ngay sau khi bị dính, văng bắn } \\
\text { máu/dịch }\end{array}$ & 113 & 98,3 \\
\hline \multicolumn{3}{|c|}{$\begin{array}{l}\text { Thực hành xứ trí khi bị phơi nhiêm do } \\
\text { dính, văng, bắn máu/dịch }\end{array}$} \\
\hline & 80 & 69,6 \\
\hline Không đúng & 35 & 30,4 \\
\hline
\end{tabular}

Khi bị dính, văng, bắn máu/dịch của người 
bệnh đa số điều dưỡng đã xử trí đúng (71,3\%) là rửa sạch ngay nơi tiếp xúc với máu/dịch của người bệnh bằng nước. Tuy nhiên vẫn còn khá cao điều dưỡng cho rằng lấy bông gạc lau máu/dịch ngay trước khi rửa (28,7\%).

Trong 115 trường hợp bị tai nạn do dính văng, bắn máu/dịch của người bệnh $(69,6 \%)$ điêu dưỡng xử trí đúng yêu cầu (điểm đạt $10 / 10$ qui trình xử trí và thời gian xử trí), bên cạnh đó tỳ lệ khá cao $(30,4 \%)$ không xử trí đúng yêu câu.

Bảng 3.6. Thức hành xử trí của điều dướng khi bị tai nạn nghề nghiệp ( $n=161)$

\begin{tabular}{|c|c|c|}
\hline $\begin{array}{c}\text { Thực hành xử trí của } \\
\text { ĐD khi bị TNNN }\end{array}$ & $\begin{array}{c}\text { Tân số } \\
\text { (n) }\end{array}$ & $\begin{array}{c}\text { Tỷ lệ } \\
\text { \% }\end{array}$ \\
\hline Đúng & 104 & 64,6 \\
\hline Không đúng & 57 & 35,4 \\
\hline
\end{tabular}

Qua kết quả cho thấy thực hành xử trí của điều dưỡng khi bị TNNN của 161trường hợp (trong đó là những người bị ít nhất một tai nạn nghề nghiệp: Bị tai nạn do vật sắc nhọn hoặc dính, văng, bắn máu/dịch hay bị cả hai tai nạn trên) trong đó tỷ lệ trả lời đúng là (64,6\%), tỷ lệ trả lời không đúng $(35,4 \%)$.

\section{BÀN LUÂNN}

Trong quá trình làm việc, ĐD không thể tránh khỏi các TNNN như bị kim tiêm, vật sắc nhọn đâm hay bị văng, bắn máu/dịch của người bệnh. Các nghiên cứu gần đây cho thấy tỉ lệ ĐD bị các tai nạn cũng khá nhiều, nếu NVYT xử trí kịp thời khi bị tổn thương có thể giảm nguy cơ phơi nhiễm rất cao. Nhiều nghiên cứu của WHO về bệnh liên quan đến nghề nghiệp của nhân viên y tể cũng đã chứng minh rằng, các bệnh lây truyền qua đường máu, trong đó bệnh VGVRB đóng vai trò quan trọng trong mô hình bệnh nghể nghiệpthể hiện nguy cơ lây nhiễm,tỷ lệ mắc,tính trầm trọng và hậu quả của bệnh đến sức khỏe và đời sống kinh tế xã hội.Khi bị tổn thương nhân viên y tế xử trí kịp thời có thể giảm nguy cơ phơi nhiếm. Kết quả nghiên cứu cho thây $(100 \%) Đ D$ thực hành đúng khi bị tai nan do vật sắc nhọn là xối ngay vết thương dưới vòi nước chảy và rửa kỷ bằng nước, sau đó sát khuẩn bằng cồn, kết quả này cao hơnnghiên cứu của tác giả Nguyễn Thị Mỹ Khánh $(85,7 \%)(7)$. Còn $(18,3 \%)$ ĐD bóp nặn máu vùng tổn thương, đây là biện pháp được khuyến cáo là không được làm vì làm vết thương dể tổn thương hơn, làm cho vi rút xâm nhập vào dễ dàng, tỷ lệ này thấp hơn nghiên cứu của tác giả Nguyễn Thúy Quỳnh $(36,9 \%)(8)$, nghiên cứu của tác giả Nguyễn Việt Hùng tại Bệnh viện Bạch Mai
$(81,1 \%)(9)$.

Khi bị dính hay văng, bắn máu/dịch của người bệnh có hơn $2 / 3 \bigoplus D$ xử trí đúng là rửa sạch ngay nơi tiếp xúc với máu/dịch của người bệnhbằng nước $(71,3 \%)$. Vẫn còn $(28,7 \%)$ ĐD lấy bông gạc lau máu/dịch, tỷ lệ này thấp hơn nghiên cứu của tác giả Trần Thị Bích Hải $(79,1 \%)(6)$, cao hơn nghiên cứu của tác giả Nguyễn Thị Mỹ Khánh $(24,5 \%)(7)$. Điều này có thể lý giải rằng, $\mathrm{DD}$ bị phơi nhiểm khi thực hiện các kỹ thuật tháo tác trên người bệnh có thể thuận tay lấy bông, gạc có sẵn trên xe tiêm nên lau trước khi đến nơi rửa sạch vết thương dưới vòi nước đó là phản xạ tự nhiên, nhưng không đúng.

\section{KẾT LUÂ̂N}

Tỷ lệ điều dưỡng bệnh viện chưa xử trí đúng sau phơi nhiễm vật sắc nhọn và văng bắn dịch tiết bệnh nhân vẫn còn cao. Bệnh viện cần tập huấn và giám sát việc xử trí sau phơi nhiễm với vật sắc nhọn ở điều dưỡng

\section{TÀI LIẸU THAM KHẢO}

1. Nguyễn Thúy Quỳnh, Nguyễn Lệ Ngânn, Dư Hồng Đức, (2009), Xác định tỉ lệ mới mắc bệnh viêm gan $B$ nghề nghiệp taii một số bệnh viện.

2. Khúc Xuyên (1999), Điều tra cơ bản thực trạng sức khỏe ngươi lao động tiếp xúc với vi sinh vật nguy hiểm (vi rút viêm gan $B$ ), Đề tài khoa học công nghê.

3. Viên Chinh Chiến, Nguyễn Thụ Thế Trâm, Đinh sĩ Hiên, (1998), Điều tra về tình trang nhiềm vi rút viêm gan $B$ trong nhân viên y tế taì một số tỉnh Miên Trung, Tóm tắt Hội nghị khoa hơ về $Y$ hoc lao đông toàn quốc lần thứ III.

4. Vỗ Hồng Minh Công, Trân Xuân Linh, Đặng Công Hân, (2009), Khảo sát tình trạng nhiếm siêu vi viêm gan $B$ của nhân viên y tế Bệnh viện Nhân dân Gia định Y học Thành phố Hồ Chí Minh, tập 13 (6).

5. Phan Công Trắng (2018), Kiến thức, thực hành và một số yếu tổ liên quan về dự phòng phơi nhiêm viêm gan vi rút $B, C$ nghề nghiệp của điêu dưỡng các khoa lâm

6. Trân Thị Bích Hải (2013), Kiến thức, thái độ, thực hành và một số yếu tố liên quan đến phòng bệnh viêm gan $B$ nghề nghiệp của điều dưỡng Bệnh viện Ung Bướu Hà Nội.

7. Nguyến Thị Mỹ Khánh (2018), Kiến thức, thưc hành phòng bệnh viêm gan $B$ nghề nghiệp của điều dưỡng lâm sàng Bệnh viện Nguyễn Đình Chiểu Bến Tre năm 2018.

8. Nguyển Thúy Quỳnh, Dư Hồng Đức, Nguyễn Lế Ngân (2009), Thực trang nhiếm HBV và các yểu tổ ảnh hưởng trong nhần viên y tế tại một số bệnh viện của Việt NamTrường Đại học Y̛ tế công cô̂ng, Hà Nội.

9. Nguyến Việt Hùng, (2008), Nghiên cứu thực trang kiến thức, thái độ, thực hành của nhân viển y tế về dự phòng cơ bản tại bệnh viện Bạch Mai 